\title{
Plasma proteomic profile of sulfur mustard exposed lung diseases patients using 2- dimensional gel electrophoresis
}

\author{
Hossein Mehrani ${ }^{1 *}$, Mostafa Ghanei ${ }^{2}$, Jafar Aslani ${ }^{2}$ and Zahra Tabatabaei
}

\author{
* Correspondence: \\ hosseinmehrani@ymail.com \\ ${ }^{1}$ Laboratory of Proteomics, and \\ Chemical Injuries Research Center, \\ Baqiyatallah University of Medical \\ Sciences, Tehran, Iran \\ Full list of author information is \\ available at the end of the article
}

\begin{abstract}
Introduction: Sulfur mustard "bis (2-chlroethyl) sulphide" (SM) is a chemical warfare agent that remains a threat to human health. The aim of this study was to identify protein expression signature or biomarkers that reflect chronic lung damages induced by SM exposure.
\end{abstract}

Methods: Prior to analysis, plasma was fractionated using ethanol precipitation. Using two dimensional SDS-PAGE; fractionated protein profiles of 20 healthy and 20 exposed patients with lung diseases were established. Selected protein spots were successfully identified with MALDI TOF MS/MS.

Results: The results show that $\alpha 1$ haptoglobin isoforms were detected in plasma of the all lung disease patients but none of the healthy controls. Amyloid A1 isoforms was also detected in plasma of the lung disease patients but none of the healthy controls. Moreover, low molecular weight proteins were enriched in ethanol supernatant compared to ethanol precipitate.

Conclusion: Our present results and previous studies suggest that ongoing tissue remodeling is involved in SM exposed lung damage patients. These finding might improve patient care and suitable therapies.

\section{Introduction}

Sulfur mustard is a chemical warfare agent that remains a threat to human health.. More than lethality, SM causes debilitating effects that can leave an exposed individual incapacitated for days, months, or years. Lung injury is a common health problem after inhalation, which leads to chronic bronchitis and interstitial lung diseases [1]. The clinical picture of the poisoning is well known from the thousands of victims during World War I and the recent Iran-Iraq conflict. In the latter, sulfur mustard was heavily used and at the present time about 30,000 victims still suffer from late effects of the agent, such as chronic obstructive lung disease, lung fibrosis, recurrent corneal ulcer disease, and chronic conjunctivitis [2]. Late complications of mustard gas exposure and main clinical findings include; chronic bronchitis, bronchiectasis and bronchiolitis obliterans (BO) [3-5]. However, Clinical manifestation in lung disorders due to sulfur mustard is different from other lung diseases, due to the fact that mustard lung is not responsive to corticosteroids. There is no common consensus about the

(c) 2011 Mehrani et al; licensee BioMed Central Ltd. This is an Open Access article distributed under the terms of the Creative Commons Attribution License (http://creativecommons.org/licenses/by/2.0), which permits unrestricted use, distribution, and reproduction in any medium, provided the original work is properly cited. 
pathophysiological basis of chronic pulmonary disease caused by this chemical warfare agent [6].

Proteomics technologies can identify and quantify novel proteins in the plasma that can function as biomarkers of the presence or severity of disease states. In general, human plasma proteome profiling is challenging. Albumin is present at about $40 \mathrm{mg} /$ $\mathrm{ml}$ and several other proteins are highly abundant including immunoglobulins (IgGs), transferrin and fibrinogen which typically constitute greater than $90 \%$ of total protein mass [7]. These abundant proteins may hinder the detection of low-abundant proteins that can be of specific interest in the search for biomarkers of disease [8]. However, it is the low abundant proteins that are most likely to be biologically relevant as the markers of a disease state. For analysis of low-abundant proteins in plasma, many strategies have been developed for the selective removal of albumin and other highabundance proteins. Albumin can be removed by immune affinity columns chromatography [9], isoelectric trapping [10], heparin chromatography [11] and peptide affinity chromatography [12]. However, it is well known that albumin and other high-abundance proteins may also act as carrier or transport proteins and thus are likely to bind many species of interest, such as peptide hormones, cytokines, and chemokines.

There are wide-ranging interests in using the proteomics approach to define markers of lung disease. Although respiratory tract lesions represent the major disability after SM exposure, only a few studies have investigated the long term pathophysiology of SM induced respiratory damages, in particular their proteomes. We have recently examined the proteomics pattern in bronchoalveolar lavage (BAL) fluid of SM exposed patients and identified families of proteins whose expression is up or down regulated compared to healthy controls [13]. Plasma proteins and peptides are from almost every tissue and cell, and their change in quantity and quality is specific not only to the tissue affected by disease, but also to the disease process itself. In addition, plasma is the most easily accessible, less invasive, and widely collected sample.

We attempted to explore plasma proteomics patterns of these patients, using ethanol fractionation. Tow-dimensional gel electrophoresis was applied and followed by MALDI-TOF MS to look for new markers in the plasma of exposed patients which may help in further understanding the nature of long term effects of mustard gas. These finding might improve patient care and finding suitable therapies.

\section{Results}

The plasma protein content of the patients and the controls are presented in Table 1. No significant differences were observed in plasma protein contents of patients and controls.

The ethanol fractionation was used to enrich low molecular weight proteins. As shown in Figure 1, most of the low molecular weight proteins were enriched in the ethanol supernatant rather than the precipitate. We found that $50 \%(\mathrm{v} / \mathrm{v})$ ethanol was more efficient in fractionating low molecular weight proteins. To avoid any protein

Table 1 Age and plasma protein concentrations of patients and control subjects ${ }^{a}$

\begin{tabular}{lll}
\hline Variables & Healthy Controls & Severe Patients \\
\hline Age (year) & $40.1 \pm 3.6$ & $43.6 \pm 2.8$ \\
Protein in plasma $(\mathrm{mg} / \mathrm{ml})$ & $71.6 \pm 3.1$ & $72.4 \pm 5.3$ \\
\hline
\end{tabular}

a. Data are mean \pm SEM ( $n=20$ in each group). 


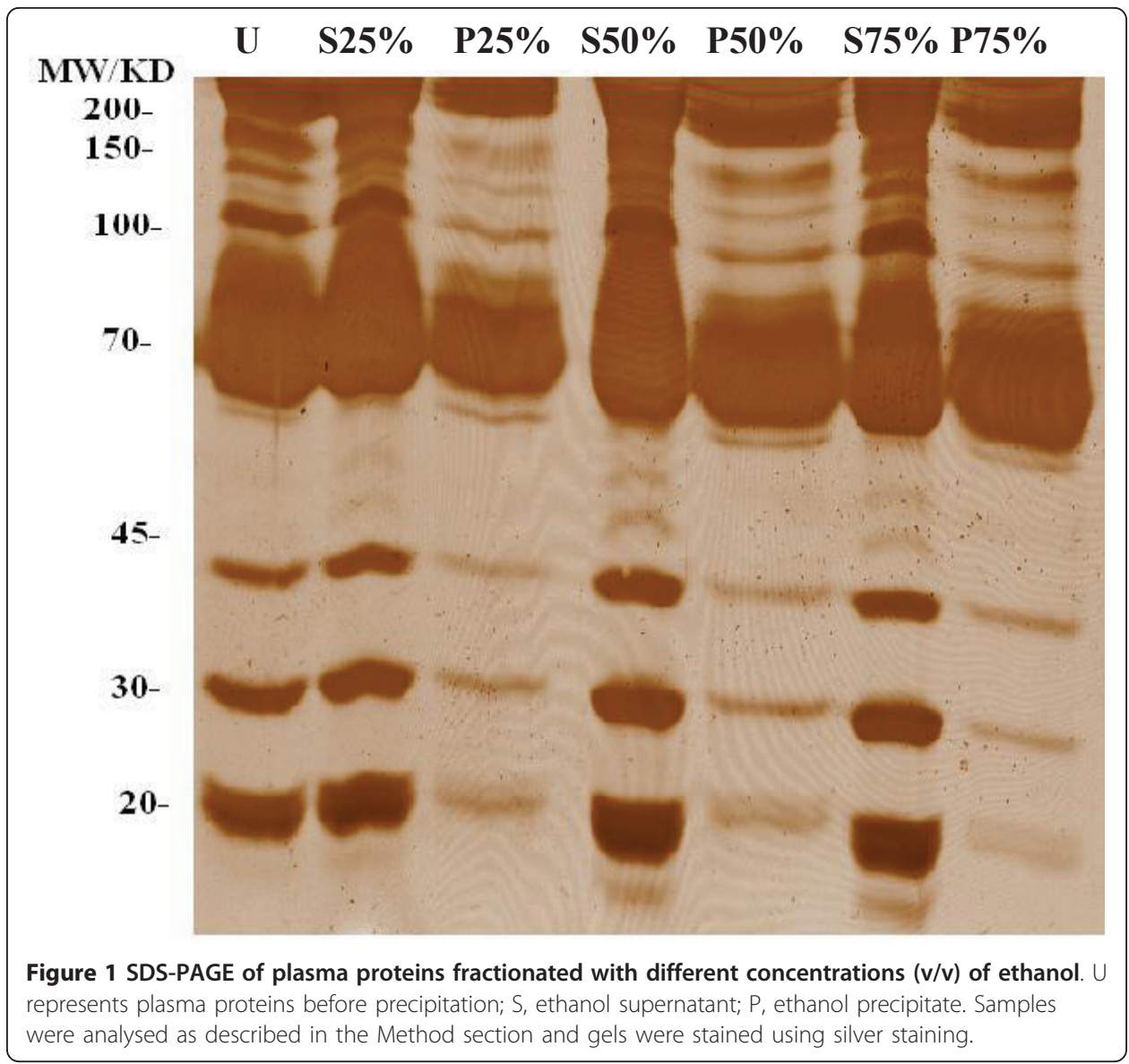

losses from the sample, we used both supernatants and precipitates of these fractions for 2-DE analysis. For the first dimension $24 \mathrm{~cm}$ IPG strips with $\mathrm{pH}$ values in the range of 4-7 were used. The proteins were resolved in homogeneous 15\% acrylamide gels in the second dimension to obtain greater resolution for small proteins. About 300 spots in each colloidal CBB-stained gel can be visualized by ImageMaster software. Representative 2-DE images of plasma profiles from a healthy control for $50 \%(\mathrm{v} / \mathrm{v})$ ethanol precipitate and ethanol supernatant are shown in Figure 2A and 2B respectively. Comparing the proteomics patterns of these two gels shows that both immunoglobulin heavy and light chains are separated in ethanol precipitate (Figure 2A) and albumin is distributed both in ethanol supernatant and precipitate (Figure 2A and 2B). Moreover, most of the small molecular weight proteins in the range of $15-50 \mathrm{kDa}$, have significantly $(\mathrm{p}<0.05)$ higher spot volume and intensity in ethanol supernatant rather than precipitate (Table 2 and Figures. 2A and 2A).

We analyzed the differences in the plasma protein patterns, comparing the gels of the diseased and healthy controls. The analysis of protein patterns of the plasma was focused on those protein spots which showed differences, comparing the patients and the controls. They were compared with Image Master 2-DE software and indicated only protein results in all cases $(100 \%)$ with the same condition. As shown in Figures 2 $\mathrm{B}$ and $2 \mathrm{C}$, twenty six protein spots were subjected to MALDI TOF MS analysis. All selected proteins and their isoforms were subsequently identified by PMF and MS/MS 


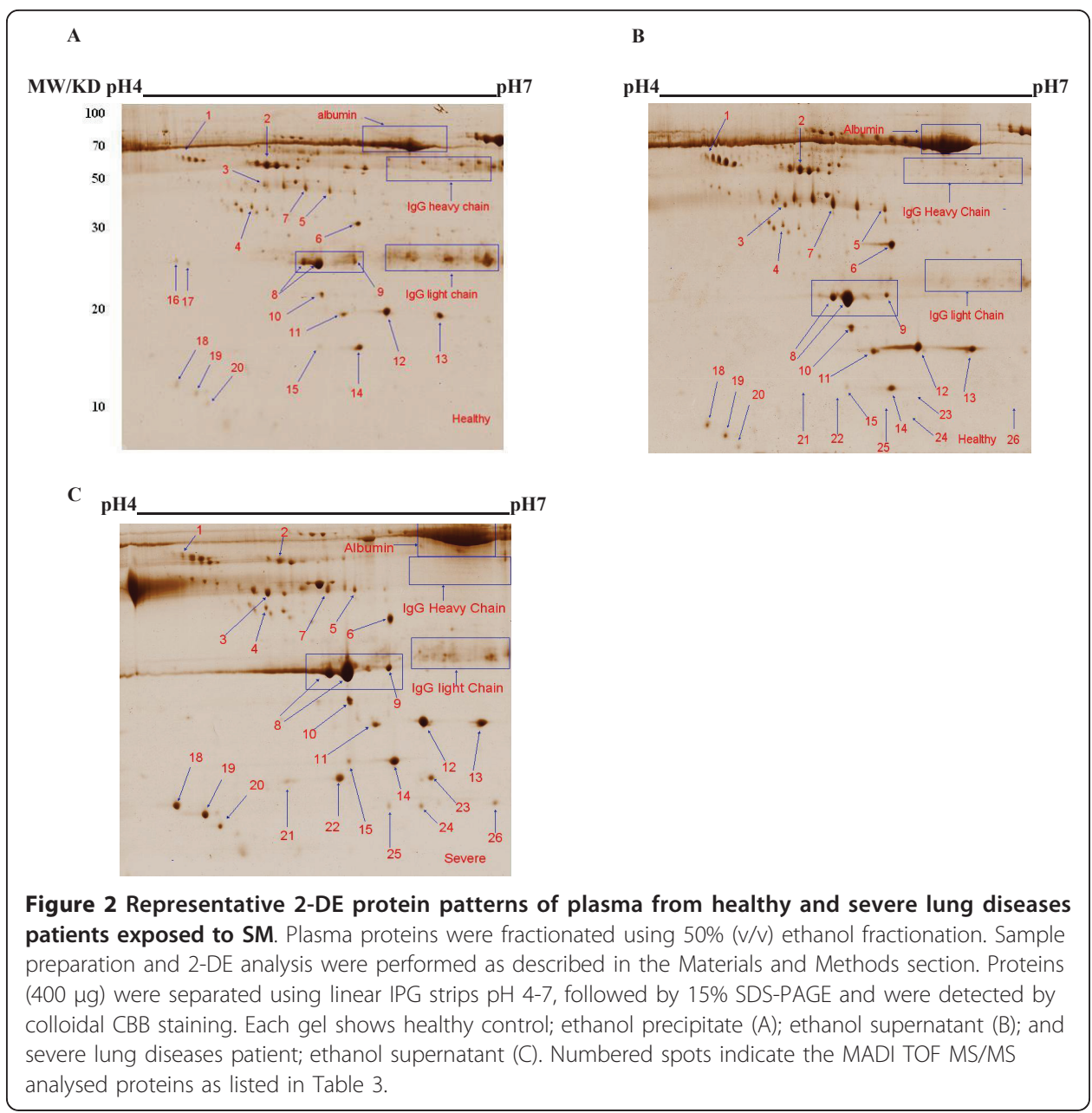

analysis. Table 3 lists the identities of the proteins and their isoforms which were analyzed in this experiment using MALDI TOF MS. Figures 2B and 2C shows the location of these protein spots in the 2-DE gels of a healthy controls and an exposed patients respectively. Volume and intensity of those protein spots which were only present in all patients' plasma but none of the healthy controls are shown in Table 4. Images from other healthy volunteers and patients were similar (data not shown).

Haptoglobin $\alpha 1$ chain isoforms (spots 21, 22 and 23) were only detected in the plasma of the severe lung diseases patients but were not detectable in healthy controls (Figure 2B and 2C). Furthermore, serum Amyloid A1 isoforms (spots 24 and 26) were only seen in the plasma of the patients but none of the healthy controls (Figure 2B and $2 \mathrm{C})$.

\section{Discussion}

In this study we present plasma proteome analysis of SM exposed patients compared to the healthy controls. Human plasma and serum represent important biological materials for disease diagnosis. However, the wide dynamic range in protein concentrations remains a major challenge in the development of diagnostic assays. Human plasma albumin and the various forms of immunoglobulin represent the most abundant proteins in the plasma, constituting up to $80 \%$ of the total plasma proteins. The 
Table 2 Comparison of spot volume and intensity in ethanol fractionated human plasma $^{a}$

\begin{tabular}{|c|c|c|c|c|c|}
\hline \multirow[t]{2}{*}{ Spot\# b } & \multirow{2}{*}{$\begin{array}{l}\text { Protein } \\
\text { Name }\end{array}$} & \multicolumn{2}{|c|}{ Ethanol Supernatant } & \multicolumn{2}{|c|}{ Ethanol Precipitate } \\
\hline & & $\%$ Volume & $\%$ intensity & $\%$ Volume & $\%$ intensity \\
\hline 1 & $\alpha 2$ HS glycoprotein & $10 \pm 1.4$ & $23 \pm 1.8^{* *}$ & $8 \pm 1.2$ & $13 \pm 1.6$ \\
\hline 2 & $\alpha 1$-antitrypsin & $160 \pm 14$ & $67 \pm 6.4$ & $170 \pm 23$ & $59 \pm 4.7$ \\
\hline 3 & Zinc $\alpha 2$ glycoprotein & $36 \pm 4.6^{* *}$ & $46 \pm 4.2^{* *}$ & $12 \pm 2.1$ & $19 \pm 4.8$ \\
\hline 4 & SP40 & $20 \pm 3.8$ & $44 \pm 2.7$ & $21 \pm 3.1$ & $39 \pm 3.2$ \\
\hline 5 & Haptoglobin & $36 \pm 4.3^{* *}$ & $51 \pm 9.0^{* *}$ & $19 \pm 2.8$ & $29 \pm 2.5$ \\
\hline 6 & Transthyretin & $137 \pm 19^{* *}$ & $68 \pm 5.6^{* *}$ & $54 \pm 13$ & $33 \pm 11$ \\
\hline 7 & Apolipoprotein AIV & $120 \pm 11^{* *}$ & $64 \pm 8.3^{* *}$ & $35 \pm 7.8$ & $37 \pm 5.2$ \\
\hline 8 & Apolipoprotein A1 & $140 \pm 12$ & $70 \pm 4.1$ & $121 \pm 13$ & $54 \pm 5.9$ \\
\hline 8 & Apolipoprotein A1 & $640 \pm 23^{* *}$ & $74 \pm 8.2$ & $405 \pm 15$ & $63 \pm 6.2$ \\
\hline 9 & Apolipoprotein A1 & $41 \pm 3.0$ & $59 \pm 6.9$ & $54 \pm 4.7$ & $36 \pm 4.1$ \\
\hline 10 & Retinol BP 4 & $53 \pm 12^{* *}$ & $58 \pm 5.8^{*}$ & $27 \pm 7.5$ & $42 \pm 5.5$ \\
\hline 11 & Haptoglobin hp2 $\alpha$ & $73 \pm 5.6^{* *}$ & $56 \pm 4.3^{* *}$ & $41 \pm 6.1$ & $36 \pm 4.2$ \\
\hline 12 & Haptoglobin hp2 $\alpha$ & $215 \pm 9.2^{* *}$ & $70 \pm 4.8$ & $170 \pm 8.5$ & $62 \pm 6.8$ \\
\hline 13 & Haptoglobin hp2 $\alpha$ & $155 \pm 8.4^{* *}$ & $64 \pm 6.8$ & $91 \pm 9.2$ & $57 \pm 6.8$ \\
\hline 14 & Transthyretin & $77 \pm 5.8$ & $56 \pm 6.8$ & $87 \pm 9.2$ & $54 \pm 6.8$ \\
\hline 15 & Transthyretin & $10 \pm 5.6$ & $7.5 \pm 6.8$ & $11 \pm 9.2$ & $8.2 \pm 6.8$ \\
\hline 18 & Apolipoprotein CIII & $123 \pm 8.4^{* *}$ & $58 \pm 6.8 * *$ & $91 \pm 9.2$ & $27 \pm 6.8$ \\
\hline 19 & Apolipoprotein CIII & $125 \pm 8.4^{* *}$ & $79 \pm 3.4^{* *}$ & $65 \pm 7.8$ & $25 \pm 4.3$ \\
\hline 20 & Apolipoprotein CII & $35 \pm 4.4^{* *}$ & $24 \pm 7.2^{* *}$ & $11 \pm 9.2$ & $8.9 \pm 6.8 \uparrow$ \\
\hline
\end{tabular}

Data are mean \pm SEM of the $\%$ volume and intensity of protein spots on the $2 \mathrm{D}$ gels multiplied by 100 . Significant difference between the samples were calculated using the Student's t-test and marked by $*$ if $p<0.05$, ** if $p<0.01$.

a. Spot numbers correspond to those in Figures $2 \mathrm{~A}$ and $2 \mathrm{~B}$

classical depletion strategy for albumin involves using hydrophobic dye Cibacron blue, a chlorotriazine dye which has high affinity for albumin [14]. As a group, the immunoglobulins represent the second most abundant proteins in the plasma or serum. It has been reported that albumin depletion may also remove some small low copy number proteins [15]. Therefore, in these experiments we used ethanol fractionation and found that this simple and low cost experimental procedure can be used for removing immunoglobulins and part of the albumin. Moreover, using 50\% (v/v) fractionation, we showed that the ethanol supernatant contains all the protein spots that were found in the ethanol precipitate and recovers more small MW proteins.

We have identified some proteins that could give a novel insight into the pathogenesis of mustard lung. One of the main findings was different isoforms of haptoglobin in the plasma of severe lung disease patients but not in healthy controls. Haptoglobin is present in normal human plasma at a concentration range of $0.3-1.9 \mathrm{mg} / \mathrm{ml}$, accounting for $0.4-2.6 \%$ of total plasma protein. Human haptoglobin is an inflammation-inducible plasma protein. It consists of 2 different types of $\alpha$ chains and a single type of $\beta$ chain connected by disulfide bridges $(\beta-\alpha-\alpha-\beta)$ giving 3 major phenotypes (Hp 1-1, Hp 2-1, Hp 2-2), the numbers 1 and 2 representing $\alpha 1$ (8.9 kDa) and $\alpha 2$ (16 $\mathrm{kDa})$ chains, respectively. The $\beta$ chain $(40 \mathrm{kDa})$ is heavier than $\alpha$ chain and is identical in all Hp types [16-19].

Our results (Figures $2 \mathrm{~B}$ and $2 \mathrm{C}$ ) show that under our experimental conditions, the $\alpha 2$ chain (spots 11,12,13) is similarly expressed in the plasma of both experimental 
Table 3 Analysis of tryptic digests with MALDI -TOF/TOF-MS (MS/MS)

\begin{tabular}{|c|c|c|c|c|c|c|c|}
\hline $\begin{array}{l}\text { Spot } \\
\text { No }\end{array}$ & Protein name & $\begin{array}{l}\text { Database }{ }^{b} \\
\text { id }\end{array}$ & $\begin{array}{l}\mathrm{MW} / \mathrm{pl} \\
\mathrm{kDa}\end{array}$ & $\mathrm{MS} / \mathrm{MS}^{\mathrm{c}}$ & $\begin{array}{l}\text { MALDI/ } \\
\text { MS }^{\mathrm{d}}\end{array}$ & $\begin{array}{l}\text { Score } \\
\text { value }\end{array}$ & $\begin{array}{l}\text { Coverage }^{f} \\
(\%)\end{array}$ \\
\hline 1 & $\begin{array}{l}\alpha 2 \mathrm{HS} \\
\text { glycoprotein }\end{array}$ & gi156523970 & $39.3 / 5.43$ & $4 / 4[57,101,88,71]$ & $7 / 9$ & 294 & 26 \\
\hline 2 & $\alpha 1$-antitrypsin & gi157831596 & $44.3 / 5.37$ & $2 / 3[58,100]$ & $9 / 13$ & 301 & 47 \\
\hline 3 & $\begin{array}{l}\text { Zinc } \alpha 2 \\
\text { glycoprotein }\end{array}$ & gi4699583 & $31.6 / 5.70$ & $4 / 7[57,36,75,58]$ & $6 / 10$ & 577 & 65 \\
\hline 4 & SP40 & gi338305 & $36.7 / 5.74$ & $4 / 4[147,65,62]$ & $7 / 12$ & 170 & 43 \\
\hline 5 & Haptoglobin & gi3337390 & $38.2 / 6.14$ & $3 / 5[46,117,70]$ & $6 / 12$ & 209 & 31 \\
\hline 6 & Transthyretin & gi114318993 & $20.2 / 5.16$ & $3 / 4[102,87,32]$ & $4 / 10$ & 276 & 55 \\
\hline 7 & Apolipoprotein AIV & gi11957960 & $45.2 / 5.28$ & $3 / 5[61,29,42]$ & $9 / 14$ & 253 & 35 \\
\hline 8 & Apolipoprotein A1 & gi178775 & $28.9 / 5.45$ & $4 / 4[54,74,57,65]$ & $7 / 16$ & 482 & 73 \\
\hline 9 & Apolipoprotein A1 & gi178775 & $28.9 / 5.45$ & $4 / 5[73,37,71,61]$ & $7 / 16$ & 584 & 79 \\
\hline 10 & Retinol BP 4 & gi18088326 & $23.0 / 5.76$ & $3 / 4[64,125,155]$ & $6 / 10$ & 472 & 58 \\
\hline $11^{*}$ & Haptoglobin hp2 $\alpha$ & gi223976 & $41.7 / 6.23$ & $2 / 3[79,36]$ & $4 / 5$ & 155 & 20 \\
\hline $12^{*}$ & Haptoglobin hp2 $\alpha$ & gi296653 & $41.5 / 6.25$ & $3 / 4[92,90,53]$ & $4 / 9$ & 379 & 23 \\
\hline $13^{*}$ & Haptoglobin hp2 $\alpha$ & gi296653 & $41.5 / 6.25$ & $3 / 5[42,43,30]$ & $5 / 13$ & 220 & 28 \\
\hline 14 & Transthyretin & gi4507725 & $15.9 / 5.52$ & $3 / 4[118,175,28]$ & $5 / 10$ & 476 & 73 \\
\hline 15 & Transthyretin & gi4507725 & $15.9 / 5.52$ & $2 / 3[114,27]$ & $3 / 8$ & 216 & 65 \\
\hline 16 & IG J chain & gi114319027 & $19.6 / 5.24$ & $3 / 4[80,43,39]$ & $4 / 4$ & 199 & 25 \\
\hline 17 & IG J chain & gi114319027 & $19.6 / 5.24$ & $2 / 3[39,28]$ & $6 / 10$ & 226 & 29 \\
\hline 18 & Apolipoprotein CIII & gi4557323 & $10.8 / 5.23$ & $2 / 3[105,33]$ & $3 / 3$ & 181 & 34 \\
\hline 19 & Apolipoprotein CIII & gi4557323 & $10.8 / 5.23$ & $2 / 3[142,58]$ & $2 / 3$ & 225 & 34 \\
\hline 20 & Apolipoprotein CII & gi4557323 & $11.2 / 5.42$ & $2 / 3[38,24]$ & $3 / 8$ & 132 & 56 \\
\hline $21^{*}$ & Haptoglobin hp1 $\alpha$ & gi3337390 & $38.2 / 6.14$ & $2 / 4[69,27]$ & $2 / 5$ & 182 & 15 \\
\hline $22^{*}$ & Haptoglobin hpla & gi3337390 & $38.2 / 5.28$ & $2 / 2[68,59]$ & $5 / 8$ & 170 & 30 \\
\hline $23^{*}$ & Haptoglobin hpla & gi337390 & $38.2 / 5.28$ & $3 / 4[63,51,53]$ & $6 / 9$ & 164 & 25 \\
\hline 24 & Serum Amyloid A1 & gi40316910 & $13.5 / 6.28$ & $3 / 5[130,110,21]$ & $4 / 7$ & 129 & 63 \\
\hline 25 & Albumin fragment & gi19626079 & $22.4 / 6.2$ & $3 / 8[82,85,103]$ & $3 / 3$ & 231 & 27 \\
\hline 26 & Serum Amyloid A1 & gi40316910 & $13.5 / 6.28$ & $3 / 3[170,130,47]$ & $6 / 9$ & 181 & 80 \\
\hline
\end{tabular}

a) Spot No. related to the annotation in Figure $2 B$ and $2 C$. Number of peaks is given as matched to the protein/total number of SNAP algorithm selected peaks in the spectrum. Mass quality was assessed using transferrin and BSA as quality control internal standards. Score/coverage for transferrin and BSA was 421/50 and 216/29 respectively. b) NRDB1 (6655203 protein sequence)

c) The column refers to the results of the MALDI-MS/MS analysis to the number and Mowse scores (in brackets) of assigned peptides.

d) The column refers to the results of the MALDI-MS PMF analysis of the number of assigned peptides to total number of measured peptide masses picked with SNAP algorithm.

e) MASCOT score value indicates the quality of database search results.

f) Sequence coverage, refers to the observed sequence coverage of the assigned protein

*. Molecular weight (MW) and $\mathrm{pl}$ are theoretical and * indicates proteins present on the gel at a MW or p/ different to these values

groups, but $\alpha 1$ chain (spots $21,22,23$ ) is only expressed in the patients plasma samples but not in the healthy controls. In our recent study of BAL fluid proteomics patterns in SM exposed patients we also found that haptoglobin isoforms were significantly elevated in moderate and severe lung disease patients compared to mild and healthy controls [13]. Acute-phase proteins are induced shortly after exposure to triggering events such as inflammation, infection, and trauma, and are thought to be part of a general defense-response in injured tissue. But, these patients have been exposed to SM more than 20 years ago. It seems that an ongoing damage is occurring in lung of these patients. A recent proteomic study has also shown that levels of haptoglobin are elevated in BAL fluid in patients with mild asthma, and reported that haptoglobin may play a role in the differentiation of fibroblast progenitor cells, suggesting a 
Table 4 Spot volume and intensity in ethanol supernatant of lung disease patients ${ }^{a}$

\begin{tabular}{llll}
\hline Spot\# b & Protein Name & \% Volume & \% intensity \\
\hline 21 & Haptoglobin hp1 $\alpha$ & $33 \pm 4.2$ & $28 \pm 5.2$ \\
22 & Haptoglobin hp1 $\alpha$ & $143 \pm 7.6$ & $78 \pm 5.3$ \\
23 & Haptoglobin hp1 $\alpha$ & $69 \pm 6.7$ & $62 \pm 3.9$ \\
24 & Serum Amyloid A1 & $28 \pm 3.2$ & $24 \pm 4.3$ \\
25 & Albumin fragment & $31 \pm 6.9$ & $26 \pm 6.4$ \\
26 & Serum Amyloid A1 & $105 \pm 9.3$ & $69 \pm 3.6$ \\
\hline
\end{tabular}

a. Spot numbers correspond to those in Figures $2 \mathrm{C}$ which were only present in all lung disease patients' plasma but none of the healthy controls.

novel role for haptoglobin in airway remodeling in patients with asthma [20]. Conversely Nishioka et al. showed that the serum concentration of haptoglobin was decreased during acute exacerbation in asthmatic children [21]. Haptoglobin isoforms and fragments are also elevated in plasma of severe acute respiratory syndrome (SARS) patients [22]. Haptoglobin plays a crucial role in defense against hemoglobin-induced oxidative stress by a mechanism thought to involve its high-affinity binding with hemoglobin and preventing iron release from hemoglobin. However, it has yet to be shown that haptoglobin itself is an antioxidant molecule [23]. Arredouani et al. [24] further described the role of haptoglobin affecting the immune system, showing that haptoglobin directly affects $\mathrm{T}$-cells and suppress $\mathrm{T}$-helper-cells through down-regulation of cytokine production.

We found that Amyloid A1 isoforms only detected in the plasma of severe lung diseases patients but not in healthy controls (Figure $2 \mathrm{~B}$ and $2 \mathrm{C}$ ). Similar results were reported for SARS patients [22]. Although serum Amyloid A1 is not as commonly used in human medicine as $\mathrm{C}$ - reactive protein (CRP), it is more sensitive to acute response than CRP $[25,26]$. Serum Amyloid A1 is an acute-phase protein that is induced, like CRP, by inflammatory mediators, including IL-6, IL- $1 \beta$, and TNF- $\alpha$, that rises in acute exacerbation of COPD [27]. Serum Amyloid A1 is secreted from the liver as the predominant apolipoprotein associated with plasma high density lipoprotein. We postulate that in our SM exposed patients ongoing tissue damage and repair (remodeling) is occurring which leads to an increase in acute phase reactant proteins such as haptoglobin and Amyloid A1.

In conclusion, this study complements our previous BAL fluid proteome analysis of patients exposed to SM gas which resulted in identification of number of differentially expressed proteins. To our knowledge this is the first study of plasma fluid proteome in SM exposed subjects. In this and our previous study the patterns of differentially expressed proteins identified in SM exposed patients are somewhat different from other lung diseases. It seems that SM exposed lung has an aberrant tissue remodeling which results in abnormal tissue architecture.

\section{Materials and Methods}

\section{Chemicals}

All chemicals used in these studies were analytical grade or equivalent and were obtained from Sigma (St. Louis, MO) unless otherwise noted. Milli Q water (18.2 M $\Omega$ ) was used throughout. 


\section{Patient population}

According to the American Thoracic Society (ATS) classification and based on our spirometric and high resolution computed tomography (HRCT) findings, the patients were classified as severe lung diseases condition. Patients group included 20 male subjects. A group of 20 healthy age-matched male individuals was used as the control. This study was approved by the ethics committee of the research center of Baqiyatallah University of Medical Sciences, and informed consent was obtained from all patients and healthy controls. All participants were free to leave the study at will. The participant patients were suffering from pulmonary disorders due to previous exposure to a single high dose of SM gas during the Iran-Iraq conflict in 1987. Inclusion criteria were as follows: documented exposure to SM and documented diagnosis of chronic pulmonary disease due to mustard gas. Exclusion criteria for the patients and the control subjects were history of a chronic disease (tuberculosis, diabetes, hypertension, heart disease, hepatic diseases, etc.), resection of one or more lobes of the lungs, pneumonia and/or acute bronchitis, cigarette smoking or substance abuse. None of the patients or control subjects had a history of allergy or asthma. All patients and controls were in a stable condition and none of the participants had been administrated corticosteroids during the two-month period immediately preceding the studies.

\section{Sample collection}

Fasting venous blood samples were collected in the morning (8-10 am). Blood samples were drawn into tubes containing K2EDTA and then immediately centrifuged at 1300 $\times \mathrm{g}$ and $4^{\circ} \mathrm{C}$ for $10 \mathrm{~min}$ according to $\mathrm{HUPO}$ plasma proteomics project recommendation [28]. Supernatant was removed to a new tube and one tablet of complete protease inhibitor cocktail (Roche, Mannheim, and Germany) was added. Then, sample were promptly frozen in aliquots and stored at $-80^{\circ} \mathrm{C}$ until used.

\section{Sample preparation}

Plasma samples were thawed at room temperature and centrifuged at $10,000 \times \mathrm{g}$ for 10 min at $4^{\circ} \mathrm{C}$. Then clear supernatants were transferred to new microfuge tubes for further processing. Total protein in plasma fluid was determined by the bicinchoninic acid (BCA) assay and employed bovine albumin as the standard (Pierce, Rockford, IL). The concentrations of proteins in plasma and different fractions were determined using a standard curve generated by the absorbance at $562 \mathrm{~nm}$.

Following procedures for ethanol fractionation were applied. All steps were performed at $4^{\circ} \mathrm{C}$. Plasma samples were diluted 1:1 (v/v) with Milli $Q$ water in a new microfuge tube and equilibrated to $4^{\circ} \mathrm{C}$ by gentle mixing (continuously on a vortex mixer at a low setting) for $10 \mathrm{~min}$. In new separate microfuge tubes containing $500 \mu \mathrm{l}$ of diluted plasma samples, different volumes of cold ethanol were added and total volume was adjusted to $1000 \mu \mathrm{l}$ with Milli Q water. Samples were incubated for an additional hour with gentle mixing on the vortex mixer and were centrifuged at 10,000 $\times g$ for $15 \mathrm{~min}$ at $4^{\circ} \mathrm{C}$. Supernatants were removed to new tubes, pellets were briefly re-centrifuged and any residual supernatant was removed and added to the previous supernatant fraction. For electrophoresis, the supernatants were dialyzed against 50 $\mathrm{Mm}$ Tris- $\mathrm{HCl}$ ( $\mathrm{pH} 7.4)$ overnight to remove ethanol. 


\section{Polyacrylamide gel electrophoresis}

For one dimensional SDS-PAGE analysis the collected ethanol supernatants and pellets were reconstituted in $50 \mathrm{mM}$ Tris- $\mathrm{HCl}$ (pH 6.8), 2\% (w/v) SDS, 0.1\% (w/v) bromophenol blue and 10\% (v/v) glycerol. Proteins were separated by mini 1-DE (10\% T resolving gels with $4 \%$ stacking gels; $10 \mu$ g protein/lane). Gels were electrophoresed at $30 \mathrm{~V}$ for $30 \mathrm{~min}$ and then at $50 \mathrm{~mA}$ per gel for $45 \mathrm{~min}$, and stained using Vorum silver staining procedure as described recently

[29]. For 2-DE analysis dialyzed ethanol supernatants and pellets were reconstituted in buffer consisting of $7 \mathrm{M}$ urea, $1 \mathrm{M}$ thiourea, $20 \mathrm{mM}$ Tris, $\mathrm{pH}$ 7.5, 4\% (w/v) 3-[(cholamidopropyl) dimethylamino]-1-propanesulfonate (CHAPS), and centrifuged at 10,000 $\times \mathrm{g}$ at room temperature for $5 \mathrm{~min}$. Supernatants were taken for 2-DE gel analysis. Protein concentration in the recovered samples was determined using a modification of the method as described by Bradford [30].

Two dimensional gels were analysed using $400 \mu \mathrm{g}$ proteins per 24-cm linear IPG strips pH 4-7 (Bio Rad) as described previously [13]. IPG strips were reduced and alkylated, and then proteins were separated in the second dimension on homogeneous $15 \%$ polyacrylamide gels in an Ettan DALTsix electrophoresis unit (GE healthcare, Uppsala, Sweden). IPG strips were placed on the top of polyacrylamide gels $(1 \times 200 \times 260$ $\mathrm{mm})$ and sealed with a solution of $1 \%(\mathrm{w} / \mathrm{v})$ agarose containing a trace of bromophenol blue. Gels were run in a running buffer, containing $25 \mathrm{mM}$ Tris, $192 \mathrm{mM}$ glycine, and $0.1 \%(\mathrm{w} / \mathrm{v}) \mathrm{SDS}$ at $2 \mathrm{~W} / \mathrm{gel}$ for $45 \mathrm{~min}$, followed by $6 \mathrm{~W} / \mathrm{gel}$ at $20^{\circ} \mathrm{C}$ until the bromophenol blue had migrated to the bottom of the gel. Gels were fixed overnight in acetic acid, methanol, water, 10:45:45 (v/v) and stained with colloidal Coomassie brilliant blue (CBB) G-250 as described previously [13].

\section{Gel analysis and protein identification}

Analysis of spot patterns was performed using ImageMaster 2D Platinum software (version 6.0; GE Healthcare). CBB stained gels were scanned in transmission scan mode using Bio-Rad GS-800 calibrated densitometer at a resolution of 600 dots per square inch (dpi). The scanned gels were saved as TIF images for subsequent analysis. Protein spots were detected automatically. Manual spot editing or deleting (of artifacts) was performed when necessary. The spots intensity, volume, or saliency was adjusted in the preview mode using Image master software. Furthermore spots on all gels were visually carefully inspected for inappropriate matching, staining artifacts, or bad spot detection and conserved for analysis. To measure the volume and intensity of protein spots on CBB-stained gels the volume and intensity of each spot was divided by the total volume or intensity of all spots of the same gel. Since this method of normalization produces extremely small values, the result was multiplied by a scaling factor of 100 , which produced spot percentage volumes or intensity. Only those spots that were reproducibly and statistically significant $(\mathrm{p}<0.05)$ in intensity or volume were used for analysis.

For mass analysis the protein spots of interest were aseptically removed under a laminar flow hood. Processing of gel plugs, trypsin digestion and MALDI TOF MS/MS analysis using a Bruker Autoflex III MALDI TOF/TOF instrument (Alphalyse, Denmark) and database searching was performed as described previously [13]. The MS and MS/MS spectra were combined and used for a database search using the Mascot 
software (Matrix science, version 2.2.03) for database searches with the selection of following criteria: Database search program: NRDB1 (6655203 protein sequence), species of origin Homo sapience, peptide ion mass tolerance 60 ppm,, MS/MS tolerance $0.2 \mathrm{Da}$, peptide cut-off of 25 , and digestion by trypsin allowing for no more than one missed cleavage. The accuracy of mass detection was $\mathrm{MH}+$ of 0.01 assuming possibility of modification of cysteine by acrylamide and oxidation of methionine. Proteins identification was based on a combination of the peptide mass fingerprint (PMF) with peptide masses, and several MS/MS spectra of selected peptides in each MALDI MS spectrum. The protein and protein isoforms shown on the identification list is based purely on the human protein database accession that gives the highest Mascot score. To the extent that the different sequence isoforms are represented in individual database accession numbers, these have been considered in the database search. Other modifications and isoforms are not considered in this analysis. The positive protein identification was based on a probability-scoring algorithm (http://www.matrixscience. com) and the 95\% confidence level for positive identification was a score $=80$

\title{
Statistical analysis
}

All data are representative of at least three independent experiments with twenty individuals in each group and are expressed as means \pm standard error of the mean (SEM). Comparisons between two groups were performed using unpaired Student's t-test. The criterion for statistical significance was $\mathrm{p}<0.05$ for all comparisons.

\begin{abstract}
Abbreviations
2-DE: 2-dimensional electrophoresis; Apo A1: Apolipoprotein A1; ATS: American Thoracic Society; BAL: bronchoalveolar lavage; BCA: bicinchoninic acid; BO: bronchiolitis obliterans; CBB: Coomassie brilliant blue; CHAPS: 3-[(cholamidopropyl) dimethylamino]-1-propanesulfonate; COPD: chronic obstructive pulmonary diseases; CRP: C- reactive protein; DTT: dithiothreitol; HRCT: high resolution computed tomography; IPG: immobilized pH gradient; K2EDTA: di-potassium ethylene di-amine tetra acetic acid; MALDI TOF: matrix assisted laser desorption ionization time of flight; MS: mass spectrometry; MS/MS: tandem mass spectrometry; PMF: peptide mass fingerprint; SARS: severe acute respiratory syndrome; SDS-PAGE: sodium dodecyl sulfate polyacrylamide gel electrophoresis; SM: sulfur mustard.
\end{abstract}

\section{Acknowledgements}

The authors are grateful to Baqiyatallah University Research Branch and Chemical Injuries

Research Center for a supporting grant. We also thank Dr. Ejvind Mørtz in Alphalyse, Denmark for mass analysis.

\section{Author details}

${ }^{1}$ Laboratory of Proteomics, and Chemical Injuries Research Center, Baqiyatallah University of Medical Sciences, Tehran, Iran. ${ }^{2}$ Department of Pulmonary Medicine and Chemical Injuries Research Center, Baqiyatallah University of Medical Sciences, Tehran, Iran.

\section{Authors' contributions}

HM carried out study design, analysis of proteomics profile, Data mining and drafted and managed the manuscript. MG participated in the design of study and patient handling. JA participated in the patient handling and funding management. ZT participated in the experimental laboratory work on proteomic profiling. All authors read and approved the final manuscript.

\section{Competing interests}

The authors declare that they have no competing interests.

Received: 19 May 2011 Accepted: 31 May 2011 Published: 7 January 2011

\section{References}

1. Ghanei M, Akbari Moqadam F, Mir Mohammad M, Aslani J: Tracheobronchomalacia and Air Trapping after Mustard Gas Exposure. Am J Respir Crit Care Med 2006, 173:304-9.

2. Kehe K, Szinicz L: Medical aspects of sulfur mustard poisoning. Toxicology 2005, 214:198-209.

3. Emad A, Rezaian GR: The diversity of the effects of sulfur mustard gas inhalation on respiratory system 10 years after a single, heavy exposure: analysis of 197 cases. Chest 1997, 112:734-8.

4. Thomason JW, Rice TW, Milstone AP: Bronchiolitis obliterans in a survivor of a chemical weapons attack. JAMA 2003, 290:598-9. 
5. Ghanei M, Tazelaar HD, Chilosi M, Harandi AA, Peyman M, Akbari HM, et al: An international collaborative pathologic study of surgical lung biopsies from mustard gas- exposed patients. Respir Med 2008, 102:825-30.

6. Ghanei M, Harandi A: Long term consequences from exposure to sulfur mustard: a review. Inhal Toxicol 2007, 19:451-6.

7. Anderson NL, Anderson NG: The human plasma proteome: History, character and diagnostic prospects. Mol Cell Proteomics 2002, 1:845-67.

8. Cho SY, Lee EY, Lee JS, Kim HY, Park JM, Kwon MS, et al: Efficient prefractionation of low-abundance proteins in human plasma and construction of a two-dimensional map. Proteomics 2005, 5:3386-96.

9. Govorukhina NI, Keizer-Gunnink A, van der Zee AG, de Jong S, de Bruijn HW, Bischoff R: Sample preparation of human serum for the analysis of tumor markers. Comparison of different approaches for albumin and gamma-globulin depletion. J Chromatography A 2003, 1009:171-8.

10. Rothemund DL, Locke VL, Liew A, Thomas TM, Wasinger V, Rylatt DB: Depletion of the highly abundant protein albumin from human plasma using the Gradiflow. Proteomics 2003, 3:279-87.

11. Lei T, He G, Wang YL, Si LS, Chiu J: Heparin chromatography to deplete high-abundance proteins for serum proteomics. Clinica Chimica Acta 2008, 388:173-8.

12. Sato AK, Sexton DJ, Morganelli LA, Cohen EH, Wu QL, Conley GP, et al: Development of mammalian serum albumin affinity purification media by peptide phage display. Biotechnol Prog 2002, 18:182-192.

13. Mehrani H, Ghanei M, Aslani J, Golmanesh L: Bronchoalveolar lavage fluid proteomic patterns of sulfur mustardexposed patients. Proteomics Clin Appl 2009, 3:1191-200.

14. Leatherbarrow RJ, Dean PD: Studies on the mechanism of binding of serum albumin to immobilized Cibacron Blue F3GA. Biochem J 1980, 189:27-34.

15. Granger J, Siddiqui J, Copeland S, Remick D: Albumin depletion of human plasma also removes low abundance proteins including the cytokines. Proteomics 2005, 5:4713-8.

16. Chen CB, Su YC, Huang T, Ho H: Differentially expressed serum haptoglobin alpha chain isoforms with potential application for diagnosis of head and neck cancer. Clinica Chimica Acta 2008, 398:48-52.

17. Kurosky A, Barnett DR, Lee TH, Touchstone B, Hay R, Arnott MS, et al: Covalent structure of human haptoglobin: a serine protease homolog. Proc Natl Acad Sci USA 1980, 77:3388-92.

18. Black JA, Chan GF, Hew CL, Dixon GH: Gene action in the human haptoglobins. 3. Isolation of the a-chains as single gene products. Isolation, molecular weight, and amino acid composition of $\alpha$ - and $\beta$-chains. Can J Biochem 1970, 48:123-32.

19. He Z, Aristoteli L, Kritharides L, Garner B: HPLC analysis of discrete haptoglobin isoform N-linked oligosaccharides following 2D-PAGE isolation. Biochem Biophys Res Commun 2006, 343:496-503.

20. Larsen K, Macleod D, Nihlberg K, Gurcan E, Bjermer L, Marko-Varga G, et al: Specific haptoglobin expression in bronchoalveolar lavage during differentiation of circulating fibroblast progenitor cells in mild asthma. J Proteome Res 2006, 5:1479-83.

21. Nishioka T, Uchida K, Meno K, Ishii T, Akori T, Imada Y, et al: Alpha-1-antitrypsin and complement component C7 are involved in asthma exacerbation. Proteomics Clin Appl 2008, 2:46-54.

22. Chen JH, Chang YW, Yao CW, Chiueh TS, Huang SC, Chien KY, et al: Plasma proteome of severe acute respiratory syndrome analyzed by two-dimensional gel electrophoresis and mass spectrometry. PNAS 2004, 101:17039-44

23. Chi Tseng CF, Lin CC, Huang HY, Liu HC, Mao SJ: Antioxidant role of human haptoglobin. Proteomics 2004, 4:2221-8,

24. Arredouani M, Matthijs P, van Hoeyveld E, Kasran A, Baumann H, Ceuppens $\mathrm{JL}$, et al: Haptoglobin directly affects T cells and suppresses T helper cell type 2 cytokine releases. Immunology 2003, 108:144-51.

25. Bozinovski S, Hutchinson A, Thompson M, MacGregor L, Black J, Giannakis E, et al: Serum Amyloid A is a biomarker of acute exacerbations of chronic obstructive pulmonary disease. Am J Respir Crit Care Med 2008, 177:269-78.

26. Jousilahti P, Salomaa V, Hakala K, Rasi V, Vahtera E, Palosuo T: The association of sensitive systemic inflammation markers with bronchial asthma. Ann Allergy Asthma Immunol 2002, 89:381-5.

27. Sapey E, Stockley RA: COPD exacerbations. 2: etiology. Thorax 2006, 61:250-8.

28. American Thoracic Society., Spirometric Classification [document on the internet]. [http://www.thoracic.org/sections/ copd/for-health-professionals/definition-diagnosis-and-staging/spirometric-classification.html].

29. Rai AJ, Gelfand CA, Haywood BC, Warunek DJ, Yi J, Schuchard MD, et al: HUPO Plasma Proteome Project specimen collection and handling: Towards the standardization of parameters for plasma proteome samples. Proteomics 2005, 5:3262-77.

30. Bradford MM: A rapid and sensitive method for the quantitation of microgram quantities of protein utilizing the principle of protein-dye binding. Anal Biochem 1976, 72:248-54.

doi:10.1186/1559-0275-8-2

Cite this article as: Mehrani et al:: Plasma proteomic profile of sulfur mustard exposed lung diseases patients using 2-dimensional gel electrophoresis. Clinical Proteomics 2011 8:2. 